\title{
NOTE ON THE FIELD OF A FAST, CHARGED PARTICLE*
}

\author{
B. A. LIPPMANN ${ }^{\dagger}$ \\ Slanford Linear Accelentor Center \\ Stanford Universily, Stanford, Califomia, 04905
}

As the velocity of a charged particle incrans, its electric fiux lin $\leq$ become more and more concentrated aboul the traneverse plane. This picture is cometimes construed to mean that the electric field is eero in front of a very fast particle. For many purposes, this is a valid approximation, but we must remernber that it is otill an approximation. No matter what the velocity of the particle, the feld abead of it never is sero. This becomes apparent if the teld compo nent along the direction of motion is integrated over the trannvense plane. Here, Gauss' Theorem cosatrainu the longitudinal field component to be finite, and the approximation that ete it equal to sero breaks down.

To see this, let $\boldsymbol{D}$ be the displacement vector along the direction of motion. The integral of $D$ over the plane traniverne to the particle motion is a relativitic invariant; it has the ame vilue in the lab gystem and in the rest gyotem, for $D$ is the sawe in both syltems, and so are the trnoverse coordinates appearing in the integral. In both the rewt ayotem and the lab system, the integral has the MKS value $9 / 2$ in front of the particle, and the ame value in back. Thun, in both syotems, $D$ must be different from seso somewhere in the trandvene plane, and in such a way that its integral over the transwerse plane in 9/2.

- Worl appported by the Department of Euerg, contrut DE - AC03 - T6SP00515

t Consultant 


\section{$S L A C / \wedge P--31$}

\section{DEO5 002580}

To illutrate theae remarke, expreasions for $D$ are derived below for a particln in freo apace (A), and a partielo in a conducting tube (B). Wo find that, in a calculation carried out to a limited order of accuracy, the fold can bo noglected in a certain region in front of the particle; howover, etiting the field equal to sero everywhere in front of the particle is impermimible, since it violates Gause' Theorem. These remarte apply when the field point is a falte distance from the particle; in contrat, as the fidd point approaches infinitesimally close to the partizle, the field acquires a aingularity correaponding to the derivative of a delta function.

\section{(A) Pratielo in Dreo Bpace.}

In the reat syatem,

$$
D_{r}=\frac{Q r^{\prime}}{4\left[r^{2}+r^{2}\right]^{3 / 2}}
$$

where we have introduced 2 cylindrical coordinate gytem with the $z$-axis along the direction of particle motion; the feld point is at $\left(n, x^{\prime}\right)$ relative to the charged particle, which is located at the origin.

In the lab oystem,

$$
D_{x}=\frac{Q_{\gamma z}}{\operatorname{sx}\left[(\gamma x)^{2}+r^{3}\right]^{3 / 2}}
$$

again uing a cylindrical coordioato oyolem; the field point in at $(r, x)$ relative to the charged particle, where $\preceq=\gamma z$.

In eitber case, we find that

$$
\int_{0} d r 2 \pi r D_{x}=\frac{q}{2}
$$

as requixed by Ganed Theorem. Note that this reull is independent of $x$ (or $x$ ). 
Suppose we integrate only between $r=0$ and $r=6 \gamma \approx$, where $c<1$ :

$$
\begin{aligned}
\int_{0}^{q} d r \operatorname{ser} D_{1} & =\frac{Q}{2}\left\{1-\frac{1}{\sqrt{1+\epsilon^{2}}}\right\} \\
& \sim \frac{Q}{2}\left(\frac{\epsilon^{2}}{2}\right)
\end{aligned}
$$

We now see that if we are calculating to order $c$ only, the field in the region from $r=0$ to $r=6$ e may be disregarded, tince its contribution to the traneverse integral is of econd order. If this in done, the remainiog integration

$$
\int_{q x}^{\infty} d r 2 \pi r D_{s}=\frac{Q}{2} \frac{1}{\sqrt{1+e^{2}}} \sim \frac{Q}{2},
$$

satiofies Gaues' Theorem to the same order of approximation. Note that $D, \neq 0$ in the region from $r=C \gamma=$ to $\infty$.

\section{(B) Partlelo in a Condueting Tube.}

First, an identity. In the region from $r=0$ to $r=1$,

$$
\frac{\delta(r-r)}{r}=\sum_{\alpha_{4}} \frac{J_{0}\left(\alpha_{n} r\right) J_{0}\left(a_{n} r^{\prime}\right)}{\frac{1}{2} J_{1}^{2}\left(a_{4}\right)}
$$

where the $\alpha_{n}$ 's are the rootw of $J_{0}\left(\alpha_{n}\right)=0$.

Therefore, for a particle located at the origin of the rest syotem, in a con. ducting tube of unit radius, the potential function is

$$
\epsilon_{0} \phi(r, z)=-\frac{1}{2 \pi} \sum_{\alpha_{n}} \frac{J_{0}\left(\alpha_{n} r\right) e^{-\alpha_{n}\left|z^{\prime}\right|}}{\alpha_{n} J_{i}^{2}\left(\alpha_{m}\right)}
$$

The components of the dielectric displacement vector are obtained from (7) by taking the negative gradient of (7); if one then applies the voual relativistic 
traneformation formulae $\left(D_{1}=D_{1 ;} D_{\perp}=\gamma D_{\perp ;} \alpha=\gamma\right)$, the dioplacement vecton in the lab aystem are obbined. For $x>0$, then wre:

$$
\begin{aligned}
& D_{r}(r, s)=\frac{q}{2 x} \sum_{n} \frac{\gamma J_{1}\left(a_{n} r\right) e^{-a_{n} \gamma t}}{J_{f}\left(a_{n}\right)} \\
& D_{2}(r, s)=\frac{q}{3 x} \sum \frac{J_{0}\left(a_{n} r\right) e^{-a_{n} g}}{J_{i}\left(a_{n}\right)}
\end{aligned}
$$

To verify Gand' Theorem, we integrate fint along the ourface of the tube to a fixed value of $x$, and then acrom the tranverw plane:

$$
\begin{aligned}
& \int_{0}^{k} d=2 \pi D_{r}=Q \sum_{\sigma_{n}} \frac{1-e^{-a_{n} \gamma t}}{a_{n} J_{1}\left(a_{n}\right)} \\
& \int_{0}^{1} d r 2 x+D_{s}=Q \sum_{a_{n}} \frac{e^{-a_{n} T}}{a_{n} J_{1}\left(a_{n}\right)}
\end{aligned}
$$

where the last integral is eavily done by recalling that

$$
\alpha_{n} r J_{0}\left(\alpha_{n} r\right)=\frac{d}{d r}\left(r J_{1}\left(\alpha_{n} r\right)\right)
$$

The sum of the two integrab in (9) is

$$
\sum_{a_{a}} \frac{q}{a_{n} J_{1}\left(\alpha_{n}\right)}
$$

This formidable-looking exprestion sums to juat $Q / 2$, as can be verified by multiplying (6) by $r$ and integrating over $r$ from sero to unity. Thus, as expected, Gauna' Theorem in again confirmed, provided we keep the exact expresion for the fields. 
If we ent $z=0$, and integrate radially ody from zero to the sasll quantity $c_{1}$

we find the resut:

$$
Q \sum_{a_{1}} \frac{\epsilon_{1}\left(a_{n} e\right)}{a_{n} J_{1}^{2}\left(a_{n}\right)}
$$

For emall e, this reduces to

$$
Q \sum_{a_{n}} \frac{e^{2}}{2 J_{1}^{2}\left(a_{n}\right)} \sim e^{2}
$$

As in (A), we again conelude that, to ordar $t$, the fleld in front of the particle, in the region from $r=0$ to $r=c$, ean be neglected, but nct ontalde this region, if Gaus: Theorem is to be antirfied.

So far, the fistance betwean the fiedd point and the particlo has implicitly

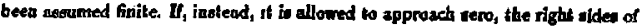
(8) and (6) become esentially the rame $(\boldsymbol{\prime}=0) . D$, then is proportional to the left aide of (G), which is equivalent to the derivalive of the delta function, and whith characterizen the singularity of the field as approaches sero.

A similar result is obtained in case (A), eines, at a appmaches sero, the prewence or absence of a conduetiag trbe of unit rodiut it immaterial.

\section{DISCLAIMER}

This report was prepared as an account of work sponsored by an agency of the Uoited States Government. Neither the Uaized Stales Governmeat acy any agency thereol, nor any of their employess maka any warranty, express or implied, of assumes any legal liability of respoasicility for the a product, or process dischosed, or represents that its ase would not infrings privately owaed rights. Reference herein to any specific commercial product, process, at service by trade name. trademark. manufarturer, or of herwise does not abcessarily constitute of imply its endostment. recomInenda'ion, of favur:ag by the United States Government or any agency thereof. The views and opinions of anthors expressed herein do not necescarily state of tefleat those of the United States Government of any agenty thercor. 